\title{
LECTURE
}

\section{Laparoscopic Presacral Neurectomy Utilizing Contact-tip Nd: YAG Laser}

\author{
James E Carter \\ Advanced Surgical Education Associates, Women's Health Center of South Orange County, Inc, Mission Viejo, \\ CA, USA
}

(Received for publication on June 13, 1995)

\begin{abstract}
The performance of the presacral neurectomy with a standard laparoscopic approach utilizing a Contact-tip Nd: YAG Laser with the GRP6 sapphire scalpel tip is feasible, effective, and safe. Patients suffering from severe disabling dysmenorrhea have had complete relief of their symptoms with up to an eighteen-month follow up. The resection of the presacral nerve plexus is associated with significant relief of symptoms. The pain impulses from the uterus which travel through the inferior hypogastric plexus into the intermediate hypogastric plexus and the superior hypogastric plexus can be interrupted by the performance of this procedure in a laparoscopic manner. The intermediate hypogastric plexus which is composed of two or three trunks lying on the vertebral body of $\mathbf{L 5}$ is the most appropriate place for the resection. The presacral neurectomy is not appropriate treatment for relief of lateral or back pain. Patients with midline pain will experience significant relief by the use of this procedure. In conclusion, the performance of the presacral neurectomy utilizing the Contact-tip Nd: YAG Laser with the GRP6 sapphire tip combined with other conservative surgery for resection of endometriosis does offer relief of dysmenorrhea and other pelvic pain and is an alternative for women wishing further childbearing and those who do not wish a hysterectomy. Twenty women in whom this procedure has been performed have reported a decrease in pain level from 9.4 (scale of $0=$ no pain to $10=$ disabling pain) to 2.0 with follow up of up to 18 months. There have been no complications with this procedure. (Keio J Med 45 (4): 332-335, December 1996)
\end{abstract}

Key words: pelvic pain, presacral neurectomy, laparoscopy

\section{Introduction}

Presacral neurectomy is useful in the treatment of severe disabling dysmenorrhea secondary to endometriosis and pelvic pain associated with pelvic inflammatory disease. ${ }^{1}$ The efficacy of presacral neurectomy for the relief of midline dysmenorrhea was demonstrated by a randomized study performed at the Johns Hopkins University School of Medicine. ${ }^{2}$ Tjaden utilized the surgical technique first described in 1899 by Jaboulay $^{3}$ and Ruggi. ${ }^{4}$

The technique of Jaboulay and Ruggi was first described in the United States by Cotte in $1937 .{ }^{5}$ In performing the surgical procedure of the presacral neurectomy, Tjaden also performed the adjunctive procedure of complete resection of endometriosis in all patients.
Pere ${ }^{6}$ and Redwine ${ }^{7}$ described a laparoscopic approach to the performance of the presacral neurectomy. The technique described by Perez and Redwine involved the use of the laparoscope through which unipolar cautery instruments were utilized for resection of the presacral nerve.

Perry and Perez have analyzed the efficacy of the laparoscopic presacral neurectomy in 87 patients. They have concluded that there is a highly significant difference among preoperative and postoperative pain levels for patients undergoing this procedure. ${ }^{8}$

Daniell $^{9}$ has described the use of the Argon Beam Coagulator and compared it to conventional techniques in 32 patients and concluded that the Argon Beam Coagulator can be used as an effective tool for this procedure.

Presented at the 921st Meeting of The Keio Medical Society in Tokyo, June 16, 1995.

Reprint requests to: Dr James E Carter, Medical Director, Advanced Surgical Education Associates, Women's Health Center of South Orange County, Inc, 26732 Crown Valley Parkway, Suite 541, Mission Viejo, CA 92691, USA 
The technique described in this paper involves the use of the Contact-tip Nd: YAG Laser (Surgical Laser Technologies, Philadelphia, PA, USA) with a standard $10 \mathrm{~mm} 0^{\circ}$ laparoscope placed in the standard position through the umbilicus. The Contact-tip Nd: YAG Laser using the GRP6 scalpel tip is a very safe and effective method of carefully delineating the presacral nerves and cauterizing and cutting the nerves for this procedure.

\section{Material and Methods}

The hypogastric plexus is formed by two or three incompletely fused trunks of the inter mesentery nerves, figure 1 . In approximately $20 \%$ of patients, there is complete fusion with resultant formation of a single nerve. The superior hypogastric plexus spreads out behind the peritoneum in a bed of loosely meshed areolar tissue, which lies upon the bodies of the 4th and 5th lumbar vertebrae. In the midline, the middle sacral artery is situated between the nerves and the anterior surface of the vertebral bodies.

A small independent nerve supply, direct from the hypogastric nerve, follows the blood supply. The uterus derives its nerve supply from the uterine portion of the pelvic plexus, figure 2 . The nerve trunks of the superior hypogastric plexus (presacral nerve) tend to be located to the left of the midline, with a tendency toward $75 \%$ being on the left and $25 \%$ at the midline, with none reported on the right. ${ }^{10}$ For this reason, the surgeon should carry out a thorough operative exposure of the nerve-bearing tissue on the left when performing a presacral neurectomy. ${ }^{11}$ The laparoscopic performance of this procedure requires that proper visualization of the superior hypogastric plexus be possible through the port that contains the laparoscope in order to ensure complete surgical exposure. Care should be exercised to expose the left ureter to obtain all connective tissue overlying the bony wall of the sacrum. The superior hemorrhoidal artery and vein will be very close to the left ureter and thus serve as an important landmark during this dissection. Removal of all nerve-bearing connective tissue between the two ureters will provide an optimum clinical result.

The technique of the presacral neurectomy is made much easier by placing the patient in steep. Trendelenburg, approximately $25^{\circ}$, and left-lateral tilt approximately $10^{\circ}$ so that the deep descending colon is displaced superiorly and to the left for good exposure of the left margin of the presacral nerve plexus. The posterior parietal peritoneum is then elevated and opened with the GRP6 scalpel tip on the Contact-tip Nd: YAG Laser at a point just to the left lateral aspect of the midline, at the anterior projection of the sacral promontory. The incision is opened upward to just below the bifurcation of the aorta and down to a point over the ventral surface of the sacrum. The position of the promontory and the right

\section{The Autonomic Nerve Trunks \\ Of The Superior Hypogastric Plexus (PRESACRAL NERVE)}

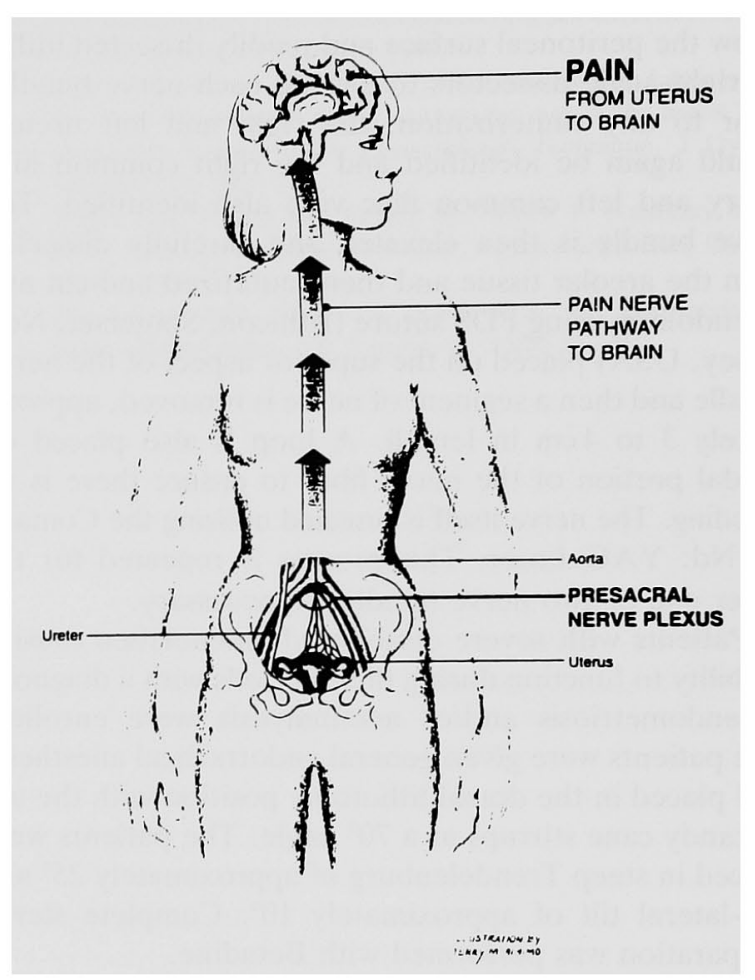

Fig 1 The anatomic nerve trunks of the superior hypogastric plexus (presacral nerve).

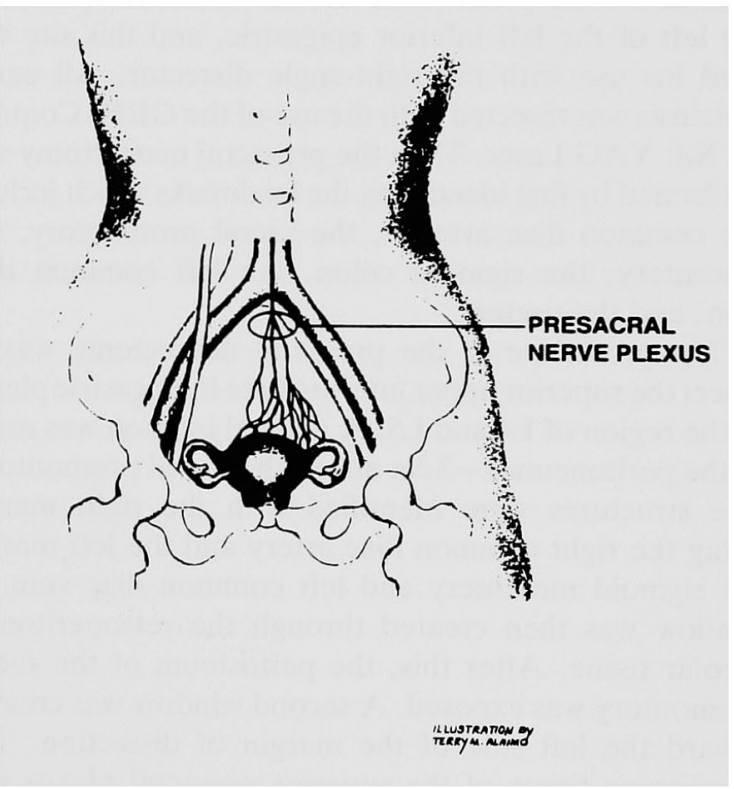

Fig 2 Presacral nerve plexus. 
ureter can readily be visualized with the laparoscope during this portion of the dissection.

Because the peritoneal dissection can be carried out with such clarity, the nerve bundles can be visualized below the peritoneal surface and readily dissected utilizing right-angle dissectors to elevate each nerve bundle. Prior to any cauterization, the right and left ureters should again be identified and the right common iliac artery and left common iliac vein also identified. The nerve bundle is then elevated and carefully dissected from the areolar tissue and then cauterized and cut and an endoloop using PDS suture (Ethicon, Somerset, New Jersey, USA) placed on the superior aspect of the nerve bundle and then a segment of nerve is removed, approximately 3 to $4 \mathrm{~cm}$ in length. A loop is also placed on caudal portion of the nerve fiber to ensure there is no bleeding. The nerve itself is resected utilizing the Contacttip Nd: YAG Laser. This process is repeated for the other one or two nerve bundles as necessary.

Patients with severe disabling dysmenorrhea causing inability to function during their periods with a diagnosis of endometriosis and/or adenomyosis were enrolled. The patients were given general endotracheal anesthesia and placed in the dorsal lithotomy position with the use of candy cane stirrups at a $70^{\circ}$ angle. The patients were placed in steep Trendelenburg of approximately $25^{\circ}$ and left-lateral tilt of approximately $10^{\circ}$. Complete sterile preparation was performed with Betadine.

A $10 \mathrm{~mm}$ trocar was inserted through the infraumbilical site after insufflation of $3 \mathrm{~L}$ of $\mathrm{CO}_{2}$ gas. One lateral $5 \mathrm{~mm}$ trocar was placed on the right of the right inferior epigastric artery and a midline $5 \mathrm{~mm}$ port was placed $4 \mathrm{~cm}$ above the pubis. One $10 \mathrm{~mm}$ trocar was placed to the left of the left inferior epigastric, and this site was used for use with the right-angle dissector. All endometriosis was resected with the use of the GRP6 Contacttip Nd: YAG Laser. Then the presacral neurectomy was performed by first identifying the landmarks which include the common iliac arteries, the sacral promontory, the mesentery, the sigmoid colon, the left common iliac vein, and the ureters.

The procedure of the presacral neurectomy was to resect the superior upper intermediate hypogastric plexus in the region of $L 4$ and $L 5$. A vertical incision was made in the peritoneum $2-3 \mathrm{~cm}$ above the sacral promontory. The structures were identified with the right margin being the right common iliac artery and the left margin the sigmoid mesentery and left common iliac vein. A window was then created through the retroperitoneal areolar tissue. After this, the periosteum of the sacral promontory was exposed. A second window was created toward the left side of the margin of dissection. The intervening tissue of the superior presacral plexus was then grasped and the tissue was coagulated and resected utilizing the GRP6 Contact-tip Nd: YAG Laser. This procedure was repeated for all other visible nerve plexes.

\section{Results}

Patients suffering from severe disabling dysmenorrhea have had complete relief of their symptoms with up to an 18-month follow-up after laparoscopic presacral neurectomy.

Although complications of the presacral neurectomy have been reported, such as postoperative adhesions, significant blood loss from injury to the middle sacral vein, urinary bladder dysfunction, chronic constipation, vaginal dryness, and painless labor, none or our patients experienced these complications. The presacral neurectomy is not appropriate treatment for relief of lateral or back pain. Patients with midline pain will experience significant relief by the use of this procedure.

The laparoscopic presacral neurectomy described in this paper has been performed on 20 patients in the past 18 months. The pain level from these women has decreased from an average of 9.4 (scale of $0=$ no pain to $10=$ disabling pain) to 2.0 with follow up of up to 18 months. There have been no complications with this procedure. The average operating time is 60 minutes and the average blood loss per case is $20 \mathrm{cc}$ 's. All patients have returned to their normal activity within one week after surgery.

Laparoscopic presacral neurectomy is a safe, effective way for treatment of disabling central dysmenorrhea.

\section{Conclusion}

The performance of the presacral neurectomy with a laparoscopic approach utilizing a Contact-tip Nd: YAG Laser with GRP6 sapphire scalpel tip is feasible, effective, and safe.

The resection of the presacral nerve plexus is associated with significant relief of symptoms. The pain impulses from the uterus which travel through the inferior hypogastric plexus into the intermediate hypogastric plexus and the superior hypogastric plexus can be interrupted by the performance of this procedure in a laparoscopic manner. The intermediate hypogastric plexus which is composed of two or three trunks lying on the vertebral body of L5 is the most appropriate place for the resection.

The performance of the presacral neurectomy utilizing the Contact-tip Nd: YAG Laser with the GRP6 sapphire tip combined with other conservative surgery for resection of endometriosis does offer relief of dysmenorrhea and other pelvic pain and is an alternative for women wishing further childbearing and those who do not wish a hysterectomy. 


\section{References}

1. Poulon M, DeCherney A: Presacral neurectomy for pelvic pain and infertility. Fertil Steril 1980; 34: 557-560

2. Tjaden B, Schlaff WD, Kimball A, Rock JA: The efficacy of presacral neurectomy for the relief of midline dysmenorrhea. Obstet Gynecol 1990; 76: 89-91

3. Jaboulay $\mathrm{M}$ : Le traitement de la mevralgie telvienne par la paaralysie du sympathique sacre. Lyon Med 1899; 90: 102

4. Ruggi G: Della Sympatectamia al Collo ed ale Adome. Policlinico; 193

5. Cotte G: Resection of the presacral nerves in the treatment of obstinate dysmenorrhea. Am J Obstet Gynecol 1937; 33: 10341040

6. Perez JJ: Laparoscopic presacral neurectomy: results of the first
25 cases. J Reprod Med 1990; 35: 625

7. Redwine DB, Perez JJ: Laparoscopic presacral neurectomy. In: Soderstrom RM, ed, Operative Laparoscopy Masters Techniques. New York, Raven Press, 1993; 157-160

8. Perry CP, Perez J: The role for laparoscopic presacral neurectomy. J Gynecol Surg 1993: 9: 165-168

9. Daniell JF, Kurtz BR, Gurley LD, LaLonde CJ: Laparoscopic presacral neurectomy versus neurotomy: use of the argon beam coagulator Compared to Conventional Technique. J Gynecol Surg 1993; 9: 169-173

10. Curtis AH, Anson BJ, Ashley SL, Jones T: Anatomy of the pelvic autonomic nerves in relation to gynecology. Surg Gynecol Obstet 1942; 75: 743

11. Rosenshein MB, Rock JA: Surgery in the Retroperitoneal Space, Philadelphia, J.B. Lippincott, 1988; 31-41 